\section{Bromopyridazinedione-mediated protein and peptide bioconjugation $\dagger$}

\author{
Vijay Chudasama, ${ }^{a}$ Mark E. B. Smith, ${ }^{a}$ Felix F. Schumacher, ${ }^{a}$ Danai Papaioannou, ${ }^{b}$ \\ Gabriel Waksman, ${ }^{b}$ James R. Baker ${ }^{a}$ and Stephen Caddick ${ }^{* a}$
}

Received 12th May 2011, Accepted 20th June 2011

DOI: $10.1039 / \mathrm{clcc12807h}$

\begin{abstract}
Bromopyridazinedione-mediated bioconjugation to a cysteine containing protein and a disulfide containing peptide is described. The conjugates are cleavable in an excess of thiol, including cytoplasmically-relevant concentrations of glutathione, and show a high level of hydrolytic stability. The constructs have the potential for four points of chemical attachment.
\end{abstract}

The published sequence of the human genome revealed encoding for only one tenth of the total proteome. The role of protein post-translational modification has therefore become of intense interest in understanding complex, physiological processes. Combining synthetic organic chemistry with molecular biology has enabled the construction of a range of proteins and peptides as probes to aid in this venture. This has allowed the introduction of synthetic post-translational modifications ${ }^{1-3}$ and a variety of fluorescent, ${ }^{4-6}$ radiolabelled $^{7}$ and affinity $\operatorname{tags}^{8-10}$ into a variety of protein and peptide structures. The selective modification of cysteine remains a popular method for achieving protein modification. This is due to its low natural abundance, high nucleophilicity and the ease with which cysteine can be introduced at desired locations in protein sequences using modern molecular biology methods. ${ }^{11-12}$

In our laboratory, we have recently become interested in the construction of protein bioconjugates that are cleavable in a reducing environment. We believe that such an approach could deliver reversible affinity or fluorescent labels, or constructs cleavable under cytoplasmic conditions with potential as prodrugs. Maleimides are known to react rapidly and selectively, but irreversibly, with thiols. However, we have recently demonstrated an approach to reversible cysteine bioconjugation using bromomaleimides, where retention of the maleimide double bond allows cleavage of the constructs via conjugate addition reaction. ${ }^{13}$ Using bromomaleimides we have been able to demonstrate the modular construction of complex bioconjugates, without requirement for reagent preactivation, that have three points of chemical attachment.

${ }^{a}$ Department of Chemistry, University College London, 20 Gordon Street,London,WC1H 0AJ,UK.E-mail: s.caddick@ucl.ac.uk; Tel: + 44 (0) 2031085071

${ }^{b}$ Institute of Structural and Molecular Biology at UCL/Birkbeck, Malet Street, London, WC1E $7 H X, U K$

$\dagger$ Electronic supplementary information (ESI) available: Full experimental details and characterisation. See DOI: $10.1039 / \mathrm{clcc} 12807 \mathrm{~h}$
Following on from this success, we are interested to determine whether the ability to construct reversible constructs is something that is restricted to maleimides or whether other cyclic or acyclic haloeneamide systems will afford alternative opportunities.

We report herein the use of both monobromo- and dibromo1,2-dihydro-pyridazine-3,6-diones (MBPDs 1 and DBPDs 2) (Fig. 1) to assemble cleavable bioconjugates. The bioconjugates generated demonstrate exceptional hydrolytic stability with the potential for four points of chemical attachment. We have previously shown that hydrolytic stability is crucial in preserving the thiol-cleavable property of bromomaleimidelinked bioconjugates. ${ }^{13 d}$

Our initial studies focused on the functionalisation of a single cysteine mutant (L111C) of the SH2 domain of the Grb2 adapter protein $3{ }^{13 a}$ a protein that does not otherwise contain any cysteine residues, with pyridazinedione (PD) 4 (100 mol eq., $37^{\circ} \mathrm{C}, 16 \mathrm{~h}$ ). No reaction was seen to occur (Scheme 1). The absence of reactivity observed with PD-4 may be rationalised by the acidic nature of its hydrazide protons. At $\mathrm{pH} 8$, PD-4 will predominantly exist in an unreactive, anionic form. ${ }^{14}$ However, treatment of protein 3 with PD-5 (100 mol eq., $37{ }^{\circ} \mathrm{C}, 16 \mathrm{~h}$ ) yielded quantitative conversion to the desired conjugate 6 (Scheme 1). As this protein sequence contains eight lysine residues, the reaction with PD-5 demonstrates remarkable selectivity for cysteine as was evidenced following an absence of reaction with Ellman's reagent. To our knowledge, this is the first reported example of a pyridazinedione being used to modify cysteine.

Encouraged by the successful functionalisation of protein 3 with PD-5, we sought to synthesise and evaluate MBPD-7 and DBPD-8 as reagents for the reversible bioconjugation of proteins. Synthesis of both $\mathbf{7}$ and $\mathbf{8}$ was achieved in high yield by the initial condensation of maleic anhydride with diethylhydrazine followed by sequential dibromination/elimination steps (Scheme 2).<smiles>[R]n1c(=O)cc(Br)c(=O)n1[R]</smiles><smiles>[R]n1c(=O)c(Br)c(Br)c(=O)n1[R]</smiles>

Fig. 1 (Di)bromo-1,2-dihydro-pyridazine-3,6-diones. 


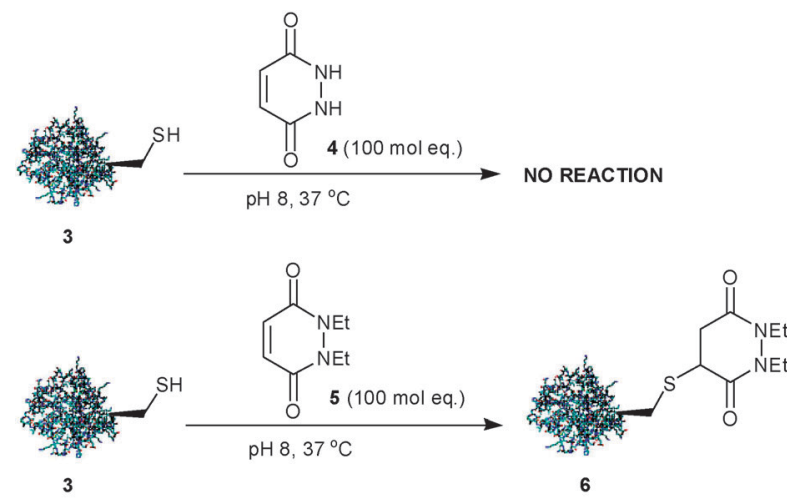

Scheme 1 Modification of Grb2-SH2 domain (L111C) 3 with 1,2dihydro-pyridazine-3,6-diones.

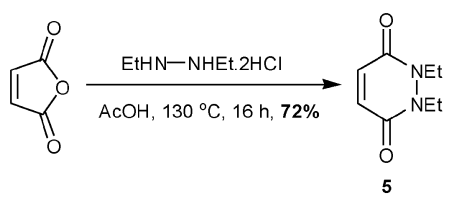

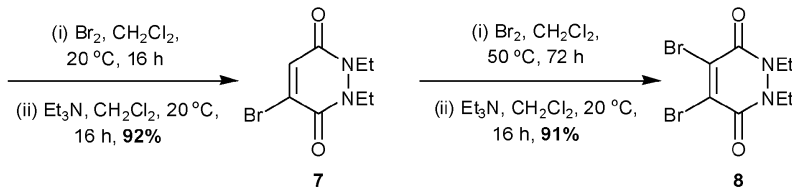

Scheme 2 Synthesis of (di)bromo-1,2-dihydro-pyridazine-3,6-diones.

Treatment of protein 3 with MBPD-7 (100 mol eq., $37^{\circ} \mathrm{C}$, $1 \mathrm{~h})$ gave quantitative conversion to the desired adduct 9 most likely via a conjugate addition-elimination mechanism. Retention of the double bond in $\mathbf{9}$ ( $c f$. adduct $\mathbf{6}$ ) created the possibility of reversing this modification in an excess of thiol. Dialysis of the crude product mixture allowed removal of excess MBPD-7. Subsequent treatment of the MBPDmodified protein with 2-mercaptoethanol (BME) (100 mol eq., $20{ }^{\circ} \mathrm{C}, 1 \mathrm{~h}$ ) gave quantitative conversion back to protein 3, highlighting the potential of bromopyridazinediones to mediate reversible protein bioconjugation (Scheme 3). Conjugate 9 displayed excellent hydrolytic stability at physiological temperature and was completely stable at $37^{\circ} \mathrm{C}$ for $5 \mathrm{~h}$.

Addition of DBPD-8 (100 mol eq., $\left.37^{\circ} \mathrm{C}, 1 \mathrm{~h}\right)$ to protein 3 gave adduct 10. Gratifyingly, addition of thioglucose, sodium salt (10 mol eq., $\left.24{ }^{\circ} \mathrm{C}, 1 \mathrm{~h}\right)$ as a second thiol nucleophile, following dialysis of the crude product mixture, gave bioconjugate 11 in high conversion. Treatment of bioconjugate 11 with an excess of BME (100 mol eq., $\left.24{ }^{\circ} \mathrm{C}, 1 \mathrm{~h}\right)$ gave disassembly of the conjugate, yielding protein 3. (Scheme 3). Bioconjugate 11 was also seen to demonstrate excellent hydrolytic stability at $37{ }^{\circ} \mathrm{C}$ for $5 \mathrm{~h}$.

The observed cleavage of protein/pyridazine constructs in an excess of thiol suggests that this scaffold could potentially form the core of novel prodrug systems. Such prodrugs could be designed and optimised to cleave in the cytoplasm of mammalian cells, which contain a relatively high concentration of the thiol glutathione (GSH) (1-10 mM). As a proof of principle, we subjected bioconjugate $\mathbf{1 1}$ to an excess of GSH $(1 \mathrm{mM})$ at physiological $\mathrm{pH}$. Bioconjugate $\mathbf{1 1}$ was seen to

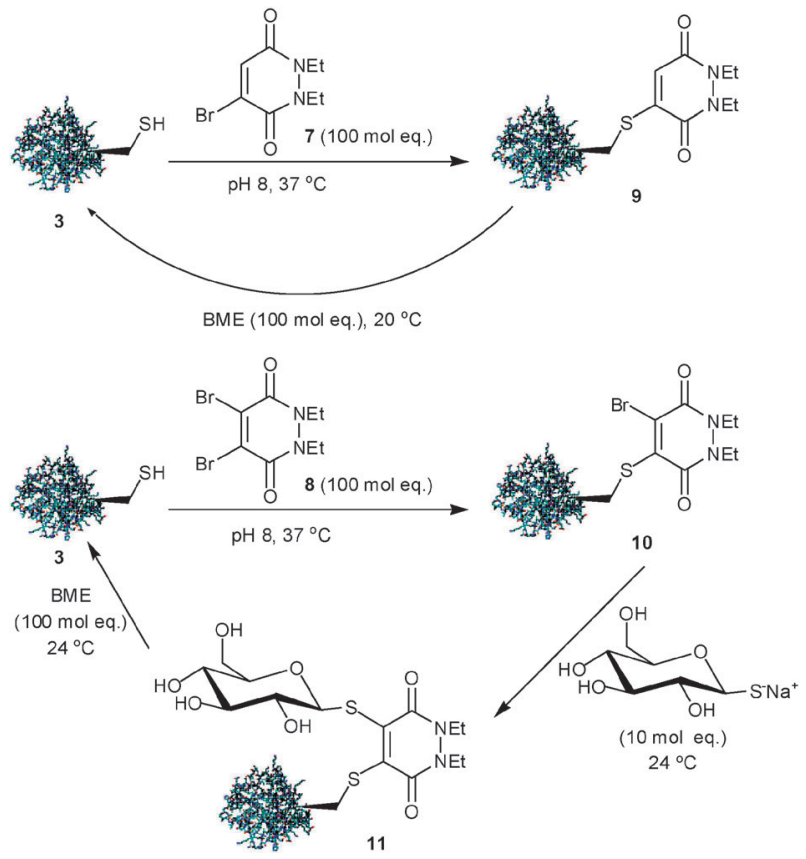

Scheme 3 Reversible modification of Grb2-SH2 domain (L111C) 3 with (di)bromo-1,2-dihydro-pyridazine-3,6-diones.

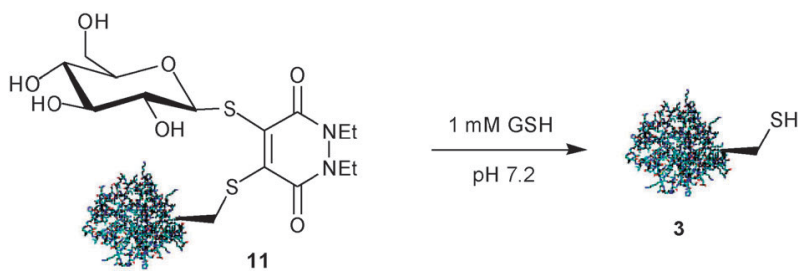

Scheme 4 Cleavage of Grb2-SH2 domain (L111C)/thioglucose conjugate $\mathbf{1 1}$ in a cytoplasmically-relevant concentration of GSH.

quantitatively disassemble, yielding protein 3 under these conditions (Scheme 4).

In addition to the functionalisation of free cysteine in proteins, we are also interested in the labeling of disulfide bonds. We have recently shown the potential of bridging disulfide bonds with dibromomaleimide bridging agents, yielding conjugates that retain biological activity. ${ }^{13 a, c} \mathrm{We}$ now wish to demonstrate how dibromopyridazinedione $\mathbf{8}$ can be used to successfully bridge the disulfide bond of peptide hormone somatostatin in a reversible manner. Thus treatment of somatostatin 12 (pH 6.2) with tris-(2-carboxyethyl)phosphine (TCEP) (1.1 mol eq.) followed by DBPD-8 $(5 \mathrm{~mol}$ eq., $20{ }^{\circ} \mathrm{C}, 2 \mathrm{~h}$ ) gave complete conversion to the desired bridged somatostatin 13. Subsequent treatment of 13 with BME (100 mol eq., $20{ }^{\circ} \mathrm{C}, 72 \mathrm{~h}$ ) gave reversion to reduced somatostatin 14 (containing $10-15 \%$ of somatostatin/BME adduct) (Scheme 5).

In conclusion, we have shown how both mono- and di-bromopyridazinediones can be used to mediate reversible protein and peptide bioconjugation. More specifically, we have demonstrated the selective modification of a free cysteine residue in a protein and also that dibromopyridazinedione $\mathbf{8}$ can be used to successfully bridge the disulfide bond of the peptide hormone somatostatin. These modifications have been shown to be reversible in an excess of thiol such as BME, and 

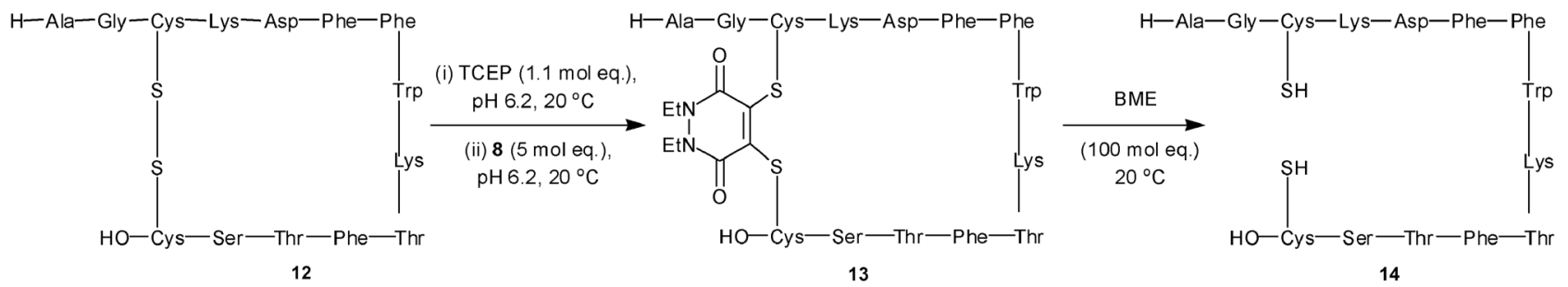

Scheme 5 Reversible bridging of the disulfide bond of somatostatin 12 using 4,5-dibromo-1,2-dihydro-pyridazine-3,6-dione 8.

the protein modification was shown to cleave in a physiologically relevant concentration of GSH.

We envisage numerous potential applications for this methodology that will exploit the thiol-cleavable and hydrolytically stable nature of this modification. These include the synthetic PTM of proteins; cleavable affinity tags for protein purification, enrichment and immobilisation; cleavable fluorophores, radiolabels and quantum dots for imaging; cleavable PEGylation for protein stabilisation; prodrugs designed to cleave in the cytoplasmic environment of cells. In addition, the potential for four points of attachment creates the possibility of the multi-labelling of protein conjugates via a single cysteine or disulfide modification. Application and further evaluation of this methodology will be reported in due course.

The authors are grateful to RCUK, EPSRC, BBSRC, UCL and the Wellcome Trust and UCLB for support of our programme.

\section{Notes and references}

1 S. I. Van Kasteren, H. B. Kramer, H. H. Jensen, S. J. Campbell, J. Kirkpatrick, N. J. Oldham, D. C. Anthony and B. G. Davis, Nature, 2007, 446, 1105.

2 B. G. Davis, Science, 2004, 303, 480.

3 K. L. Kiick, E. Saxon, D. A. Tirrell and C. R. Bertozzi, Proc. Natl. Acad. Sci. U. S. A., 2002, 99, 19.
4 K. Kikuchi, Chem. Soc. Rev., 2010, 39, 2048.

5 K. Lymperopoulos, A. Kiel, A. Seefeld, K. Stohr and D.-K. Herten, ChemPhysChem, 2010, 11, 43.

6 N. Johnsson and K. Johnsson, ACS Chem. Biol., 2007, $2,31$.

7 V. Tolmachev and S. Stone-Elander, Biochim. Biophys. Acta, Gen. Subj., 2010, 487.

8 A. Dirksen, S. Yegneswaren and P. E. Dawson, Angew. Chem. Int. Ed., 2010, 49, 2023.

9 A. E. Speers and B. F. Cravatt, J. Am. Chem. Soc., 2005, 127, 10018.

10 S. H. L Verhelst, M. Fonovic and M. Bogyo, Angew. Chem., Int. Ed., 2007, 46, 1284.

11 R. L. Lundblad, Chemical Reagents for Protein Modification, CRC Press, Boca Raton, FL, 3rd edn, 2005.

12 J. M. Chalker, G. J. L. Bernardes, Y. A. Lin and B. G. Davis, Chem.-Asian J., 2009, 4, 630.

13 (a) M. E. B. Smith, F. F. Schumacher, C. P. Ryan, L. M. Tedaldi, D. Papaioannou, G. Waksman, S. Caddick and J. R. Baker, J. Am. Chem. Soc., 2010, 132, 1960; (b) L. M. Tedaldi, M. E. B. Smith, R. Nathani and J. R. Baker, Chem. Commun., 2009, 6583; (c) F. F. Schumacher, M. Nobles, C. P. Ryan, M. E. B. Smith, A. Tinker, S. Caddick and J. R. Baker, Bioconjugate Chem., 2011, 22, 132; (d) C. P. Ryan, M. E. B. Smith, F. F. Schumacher, D. Grohmann, D. Papaioannou, G. Waksman, F. Werner, J. R. Baker and S. Caddick, Chem. Commun., 2011, 47, 5452; (e) M. E. B. Smith, S. Caddick and J. R. Baker, Patent applications WO 2011/018611 A1 (reversible covalent linkage of functional moieties), WO 2011/018612 A2 (thiol protecting group), WO 2011/018613 A1 (functionalization of solid substrates).

14 A. Albert and J. N. Philips, J. Chem. Soc., 1956, 1294. 